\title{
Issues Resolved and Unresolved in Pathological Narcissism
}

\author{
Aidan G.C. Wright \\ Elizabeth A. Edershile \\ University of Pittsburgh
}

This paper has been accepted for the June 2018 issue of Current Opinion in Psychology that is focused on Personality Disorders. This is the accepted version of the article, and has not been copy-edited.

Please address correspondence to Aidan G. C. Wright, Department of Psychology, University of Pittsburgh, 4119 Sennott Square, 210 S. Bouquet St., Pittsburgh, PA 15260, Email: aidan@pitt.edu 


\begin{abstract}
Narcissism is one of the oldest personality constructs, and yet debates about its definition and structure have been a topic of intense debate over the past decade. Recent independent reviews of the literature have proposed conceptually identical triarchic structural models of individual differences in pathological narcissism. In each model entitlement serves as the core of the construct, and its expression is moderated by basic personality/temperament to manifest in exhibitionism or vulnerability. However, the clinical observation that individuals high in pathological narcissism vacillate between grandiose and vulnerable states remains understudied and poorly understood. We review the recent research that has driven the contentious debates, emerging points of consensus, and necessary future directions for research.
\end{abstract}




\section{Highlights}

1. Pathological narcissism manifests in narcissistic grandiosity and vulnerability

2. Broad agreement exists that grandiosity reflects unique aspects narcissism

3. Vulnerability likely reflects general personality pathology

4. Dynamic within-person relationships between grandiosity and vulnerability are poorly understood 


\section{Issues Resolved and Unresolved in Pathological Narcissism}

Narcissism is one of the oldest personality constructs, and yet remains one of the most hotly debated $[1,2]$. The past decade has seen a rapid expansion of narcissism research, fueled in large part by increased interest in the diverse ways narcissism may manifest [3,4].

Consequently, this has triggered a rise in new measurement development aimed at capturing the various aspects of narcissism [e.g., 5,6,7,8,9]. However, findings across studies using different measures have often resulted in a puzzling mix of results, which has led to debates about measure adequacy and questions about the theoretical coherence of the construct [e.g., 4,10,11]. We review the principal issues leading up to this fractured state of affairs, emerging points of consensus, and necessary future directions for research.

\section{A Construct Divided: Narcissistic Grandiosity and Vulnerability}

At the root of definitional debates in narcissism is the Diagnostic and Statistical Manual of Mental Disorder's (DSM) decision to initially emphasize, and then selectively retain over successive revisions, the overtly grandiose features in its criteria for narcissistic personality disorder (NPD) [12,13]. In contrast, clinical theory has emphasized both grandiose and vulnerable features [e.g., 3,14-18]. Although the reasons are likely multiple, one must speculate whether this disconnect is responsible for the striking neglect of NPD in psychiatric research. With the exception of several early small-sample studies by Gunderson and Ronningstam $[19,20]$, there have been few empirical investigations designed to study individuals diagnosed with NPD per se. ${ }^{1}$ Indeed, we are aware of only one dataset in the past decade designed as a case-control study for NPD [see e.g., 21,22]. When studies have used clinical samples, any focus on NPD is largely in secondary analyses [e.g., 23,24] or as part of an omnibus examination of personality disorders [e.g., 25].

\footnotetext{
${ }^{1}$ Note that we are not arguing that narcissism is best represented by a categorical DSM diagnosis, rather we are merely using this as an example of psychiatry researchers' disregard for the construct.
} 
Ironically, the criteria spurned by the clinical community spawned a measure and cottage industry of narcissism research in basic personality psychology. The Narcissistic Personality Inventory $[26,27]$ was initially developed to measure the DSM's articulation of narcissism, has since enjoyed use in thousands of studies [2,3,4], and until recently was the overwhelmingly most used measure of narcissism ( $77 \%$ of studies on narcissism used it from 1985-2006; [2]). The NPI has its detractors and defenders (the critiques and rejoinders have been well summarized elsewhere [e.g., 4,2]), but regardless of one's perspective, all agree that it is exclusively a measure of grandiosity, lacking in appreciable vulnerable content. Thus, until approximately ten years ago, the bulk of the narcissism literature was based on a single measure of grandiose narcissism. Although this did not prevent the accumulation of a body of work with important findings and revelations, it contributed to an incomplete picture of pathological narcissism as described in the clinical literature (i.e., inclusive of vulnerability). Several authors have characterized this discrepancy as stemming from different conceptualizations of narcissism across social/personality psychology and psychiatry/clinical psychology [3,28,29]. However, given the NPI's provenance, we believe this characterization fails to capture the intellectual heritage of the discrepancy, and instead it reflects an issue of measurement.

There were notable exceptions to this trend, including seminal work by Wink [30], and the development of the Hypersensitive Narcissism Scale [31]. However, looking at the citation patterns for each of these, one can see that both enjoyed only modest interest until approximately ten years ago, at which point their annual citation rates increased dramatically. These patterns are reflective of a marked rise in interest in narcissistic vulnerability. Although the causes for this eruption of research on narcissistic vulnerability are difficult to pinpoint, early publications by different research groups [e.g., 3,28] and development of the Pathological Narcissism Inventory [5,32] were clear catalysts. Additional measures that include prominent vulnerability scales, such as the Five-Factor Narcissism Inventory [6], followed several years later and have continued to fuel the trend. 
On the one hand, renewed interest in and development of novel tools to study narcissistic vulnerability has begun to harmonize empirical investigations with clinical theory. On the other hand, the now voluminous research on the nomological networks of grandiosity and vulnerability has emphasized the longstanding difficulty of reconciling and integrating two seemingly incompatible dimensions under one construct. That is to say, traditional concepts like the "mask model," that argued that outward grandiosity compensates for inner vulnerability have no more empirical support now than they did in the past, and several authors have shown that the patterns of correlations for measures of grandiosity and vulnerability with criterion measures are largely divergent if not incompatible [33-37]. This has led to questions of whether there may in fact be diverse "subtypes" of narcissism, or, more broadly, whether grandiosity and vulnerability even reflect the same core construct. As noted above, others, particularly clinical theorists, have viewed the two manifestations of narcissism as emerging from the same core pathology. Ultimately, rather than clarify the empirical landscape by aligning it with theoretical propositions, the explicit interest in vulnerability and its measurement has contributed to a more fractured state of the science.

\section{Rapprochement: Structural Integration}

Despite the perceived lack of coherence between grandiosity and vulnerability, within the last year there has been two virtually identical proposals, by Krizan and Herlache [1] and Miller and colleagues [2], for integrating grandiosity and vulnerability within a single structural model of narcissism. Each of these proposals arrived at the same structure from separate reviews of the literature with distinct emphases. Both groups accentuate an essential core of narcissism, as well as moderation in its expression as a function of underlying temperament [1] or personality [2]. We refer to the core here as entitlement as others have before us [38,39], and refer to the two moderating dimensions as exhibitionism and vulnerability. Krizan and Herlache link exhibitionism and vulnerability to approach and avoidance systems, whereas Miller and colleagues, operating from the framework of the Big Five personality traits, link these to 
extraversion and neuroticism. Regardless of the terminology, these are, in effect, the same model. Entitlement/self-importance/antagonism is placed at the core, and its expression is moderated by other features of the individual's personality to be either exhibitionistic/extraverted or vulnerable/neurotic.

Due in large part to the persistent lack of agreement on the definition and core features of narcissism, a host of measures have been developed to assess the construct, which in turn contributed to the diversity of results and further lack of agreement. The above-mentioned novel organization (Entitlement, Exhibitionism, and Vulnerability) resolves many of the seemingly discrepant results by being inclusive enough to accommodate most measures and narrow enough to be summarized in a three-domain structure. Table 1 shows where scales of different narcissism measures fall with respect to these three domains.

In our opinion, this structure organizes the growing field of measures, and provides a synthetic framework for understanding existing results and the manifestation of dispositional individual differences in pathological narcissism. We would further argue, based not only on the accumulated body of research on narcissistic vulnerability's nomological net [e.g., 33-37,40], but also recent structural research on personality disorder features [41-42], that high vulnerability reflects a narcissistic character structure operating at a borderline level of functioning, as has been articulated by clinical theorists [e.g., 43]. This explains the diffuse pattern of associations between vulnerability scales and virtually all DSM personality disorders and pathological personality disorder traits as it captures all personality disorders with similar levels of functioning. Moreover, narcissistic vulnerability is not merely neuroticism. Although individuals high in narcissistic vulnerability are likely to endorse many of the items on a neuroticism scale, as they suffer from bouts of low mood, anxiety, anger, and affective instability, narcissistic vulnerability also contains themes of interpersonal detachment and antagonism that are not central to neuroticism. By the same token, individuals high in narcissistic vulnerability are likely to endorse low conscientiousness, and elevated disinhibition, 
in line with their tendency to become behaviorally dysregulated. Consistent with the view in the DSM Section II, the perspectives offered by other theorists, and structural models of personality pathology, the grandiose features are those that are unique to narcissism (or cut across a much narrower range of near neighbor pathologies). In the framework of the DSM- 5 Section III Alternative Model of Personality Disorders, the material specific to NPD listed in Criterion A largely encompasses the vulnerable features, the traits in Criterion B (Grandiosity, Attention Seeking) cover the exhibitionistic features, and entitlement can be found in both the Criterion A and B descriptors.

Thus, we would argue that the "triarchic" model of narcissism [1,2] moves the field toward consensus on the dispositional structure of narcissism, suggesting that narcissism covers a range of manifestations that are continuously distributed leading to finely-graded individual differences, and not grandiose and vulnerable subtypes. We suggest that what has been termed narcissistic vulnerability is consistent with the broad deficits described as borderline pathology in clinical theory, and has major implications for differences in level of functioning among individuals who possess the core grandiose narcissistic features (entitlement and exhibitionism). Entitlement and exhibitionism can also be costly and impairing. However, unlike vulnerability, entitlement and exhibitionism may also result in gain or benefit, especially in the short term. Individual differences in the specific blends of these domains lead to a highly heterogeneous narcissism phenotype.

\section{Moving Forward: Studying Dynamic Within-Person Processes}

Despite the emerging consensus on the structure of narcissistic traits, questions remain about potentially important within-person dynamic processes. In other words, clinical observation has routinely described fluctuation between grandiose and vulnerable states that is not well captured by the broad individual differences described in the previous section [15-18]. These views have contributed to a shift in basic personality psychology from the study of the structure of individual differences to dynamic processes that give rise to dispositional traits [44- 
45]. This perspective recognizes that individuals may have a "preferred" set-point, which reflects their trait level, around which they fluctuate across time and situations. Thus, individuals high in pathological narcissism may dispositionally spend more time in either grandiose or vulnerable states, but will from time to time oscillate from one to the other, accounting for the clinical observation of dynamic processes within a single person.

Research on these dynamic processes has lagged behind research examining the dispositional manifestation of narcissism, although there have recently been some promising advances. Gore and Widiger [46] showed, and this has since been replicated by Hyatt and colleagues [47], that when individuals are selected for matching a description of a grandiose narcissist, not only are they rated high in grandiosity, but their raters also describe bouts or periods where they exhibit vulnerable features. The opposite pattern is not true, consistent with our view that vulnerability reflects non-specific personality pathology. Nevertheless, this crosssectional research is strongly suggestive of the vacillating pattern described in the clinical narcissism literature.

Ultimately, to fully understand these dynamic within-person processes, research that adopts an intensive longitudinal design will be needed. Some such research exists, although it has largely focused on self-esteem instability [48-49] or focused solely on grandiosity [50]. Furthermore, the results from this prior work have been equivocal, making it unclear whether narcissism is related to fluctuations in functioning. However, many of these studies suffered from major limitations, and some of the more recent work using the most sophisticated designs has been more promising [e.g., 49]. Additionally, as Wright and Simms [51] showed, virtually all manifestations of personality pathology fluctuate from day to day, including features relevant to narcissism, suggesting that the minimum requirement of variability across time in grandiosity and vulnerability is likely to be present. Nevertheless, work designed to measure fluctuation in grandiosity and vulnerability, and potential switches between states, needs to be undertaken. 
Finally, evidence of fluctuation and/or switching between states across time is merely the first step needed to understand the dynamic processes of narcissism. Clinical theory and research in related domains (e.g., borderline personality pathology) both indicate that any observed variability is likely the result of the individual attempting to regulate self, affect, and their interpersonal field [52]. For example, Wright and colleagues [24] showed that the higher a patient's NPD features, the more likely they were to respond to perceptions of dominance when interacting with another person with negative affect and quarrelsome behavior; the negative affect served as a mediator between perceptions of dominance and quarrelsome behavior. This suggests that perceiving another as asserting their dominance or taking control triggers individuals high in NPD features, resulting in dysregulated affect and ultimately hostile behavior. More such research that focuses on the contingencies and eliciting factors of narcissistic pathology is needed. It holds the promise to identify targets for intervention that might disrupt the maintenance mechanisms of the pathology.

\section{Conclusion}

In summary, pathological narcissism is reflected in a broad array of thoughts, feelings, and behaviors. At its core are entitled motivations, expectations, and beliefs, that when coupled with individual differences in certain domains of personality, namely extraversion/approachorientation and neuroticism/avoidance-orientation, manifests in dispositionally grandiose or vulnerable presentations. This much is agreed upon. Theory and emerging research additionally suggest that pathologically narcissistic individuals do or can vacillate between grandiose and vulnerable states. However, a great deal more systematic research using temporally sensitive designs (e.g., ambulatory assessment) is needed to study these putative dynamic phenomena to (a) empirically describe the phenomena, (b) establish norms, and (c) evaluate potential triggers and contingencies. 


\section{References}

1. **Krizan, Z., \& Herlache, A. D. (in press). The narcissism spectrum model: A synthetic view of narcissistic personality. Personality and Social Psychology Review.

A review of the literature that proposes a novel theoretical and structural model to integrate the research on narcissism across disparate fields. The structural model in one of two that is highly similar and to emerge around the same time, and promises to reconcile discrepancies in the research on individual difference in narcissism.

2. ${ }^{* *}$ Miller, J. D., Lynam, D. R., Hyatt, C. S., \& Campbell, W. K. (2017). Controversies in narcissism. Annual Review of Clinical Psychology, 13, 291-315.

An up-to-date review of the literature that focuses on controversies in the literature. In addition, the authors propose a novel structural model for individual differences in narcissism that is based on the domains of the five-factor model.

3. ${ }^{*}$ Cain, N.M, Pincus, A.L., \& Ansell, E.B. (2008). Narcissism at the crossroads: Phenotypic description of pathological narcissism across clinical theory, social/personality psychology, and psychiatric diagnosis. Clinical Psychology Review, 28, 638-656.

A classic review of the theoretical and empirical literature spanning psychiatry, clinical psychology, and social/personality psychology.

4. Pincus, A. L., \& Lukowitsky, M. R., (2010). Pathological narcissism and narcissistic personality disorder. Annual Review of Clinical Psychology, 6, 421-446.

5. ${ }^{* *}$ Pincus, A.L., Ansell, E.B., Pimentel, C.A., Cain, N.M., Wright, A.G.C., \& Levy, K.N. (2009). The initial development and derivation of the Pathological Narcissism Inventory. Psychological Assessment, 21(3), 365-379.

The pathological narcissism inventory (PNI) was a catalyst in the recent surge in narcissism research focusing on narcissistic vulnerability. This paper describes its initial development and provides various clinical correlates that suggest the importance of tracking both grandiosity and vulnerability in clinical settings. 
6. Glover, N., Miller, J.D., Lynam, D.R., Crego, C., \& Widiger, T.A. (2012). The five-factor narcissism inventory: A five-factor measure of narcissistic personality traits. Journal of Personality Assessment, 94(5), 500-512.

7. *Back, M. D., Küfner, A. C. P., Dufner, M., Gerlach, T. M., Rauthmann, J. F., \& Denissen, J. J. A. (2013). Narcissistic admiration and rivalry: Disentangling the bright and dark sides of narcissism. Journal of Personality and Social Psychology, 105, 1013-1037.

This paper describes a new model and measure of diverse manifestations of narcissistic grandiosity.

8. Campbell, W. K., Bonacci, A. M., Shelton, J., Exline, J. J., \& Bushman, B. J. (2004). Psychological entitlement: Interpersonal consequences and validation of a self-report measure. Journal of personality assessment, 83(1), 29-45.

9. Gebauer, J. E., Sedikides, C., Verplanken, B., \& Maio, G. R. (2012). Communal narcissism. Journal of Personality and Social Psychology, 103, 854-878.

10. Wright, A.G.C. (2016). On the Measure and Mismeasure of Narcissism: A Response to "Measures of narcissism and their relations to DSM-5 pathological traits: A critical reappraisal." Assessment, 23(1), 10-17.

11. Miller, J. D., Lynam, D. R., \& Campbell, W. K. (2016). Measures of narcissism and their relations to DSM-5 pathological traits: a critical reappraisal. Assessment, 23, 3-9.

12. American Psychiatric Association. (1980). Diagnostic and statistical manual of mental disorders ( $3^{\text {rd }}$ ed.). Washington D.C.: Author.

13. American Psychiatric Association. (2013). Diagnostic and statistical manual of mental disorders ( $5^{\text {th }}$ ed.). Washington D.C.: Author.

14. Ronningstam, E., \& Gunderson, J. (1991). Differentiating borderline personality disorder from narcissistic personality disorder. Journal of Personality Disorders, 5, 225-232.

15. Ronningstam, E. (2011). Narcissistic Personality Disorder in DSM-V-In Support of Retaining a Significant Diagnosis. Journal of Personality Disorders, 25(2), 248-259. 
16. Kernberg, O. (2007). The almost untreatable narcissistic patient. Journal of American Psychoanalytic Association, 55(2), 503-539.

17. *Pincus, A.L., Cain, N.M., \& Wright, A.G.C. (2014). Narcissistic grandiosity and narcissistic vulnerability in psychotherapy. Personality Disorders: Theory, Research, and Treatment, 5(4), 439-443.

Three cases of pathological narcissism are described to illustrate the within-person manifestations of both grandiosity and vulnerability.

18. *Wright, A.G.C. (2014). Integrating trait and process based conceptualizations of pathological narcissism in the DSM-5 era. In A. Besser (Ed.) Handbook of psychology of narcissism: Diverse perspectives (pp. 153-174). Hauppauge, NY: Nova Science Publishers. This chapter provides a framework for how contemporary perspectives on traits and dynamic processes can be integrated, and two clinical cases are used as exemplars.

19. Gunderson, J.G., Ronningstam, E., \& Bodkin, A. (1990). The diagnostic interview for narcissistic patients. Archives of General Psychiatry, 47(7), 676-680.

20. Gunderson, J.G., Ronningstam, E. (2001). Differentiating narcissistic and antisocial personality disorders. Journal of Personality Disorders, 15(2), 103-109.

21. Ritter, K., Dziobek, I., Preißler, S., Rüter, A., Vater, A., Fydrich, T., ... \& Roepke, S. (2011). Lack of empathy in patients with narcissistic personality disorder. Psychiatry research, 187(1), 241-247.

22. Vater, A., Schröder-Abé, M., Ritter, K., Renneberg, B., Schulze, L., Bosson, J. K., \& Roepke, S. (2013). The narcissistic personality inventory: a useful tool for assessing pathological narcissism? Evidence from patients with narcissistic personality disorder. Journal of Personality Assessment, 95(3), 301-308.

23. Miller, J. D., Campbell, W. K., \& Pilkonis, P. A. (2007). Narcissistic personality disorder: Relations with distress and functional impairment. Comprehensive Psychiatry, 48, 170 -177. 
24. Wright, A. G. C., Stepp, S. D., Scott, L. N., Hallquist, M. N., Beeney, J. E., Lazarus, S., \& Pilkonis, P. A. (in press). The effect of pathological narcissism on interpersonal and affective processes in social interactions. Journal of Abnormal Psychology.

25. Ansell, E.B., Wright, A.G.C., Markowitz, J.C., Sanislow, C., Hopwood, C.J., Zanarini, M., Yen, S., Pinto, A. \& Grilo, C.M. (2015). Personality disorder risk factors for suicide attempts over 10 years of follow-up. Personality Disorders: Theory, Research, and Treatment, 6(2), 161-167.

26. Raskin, R., \& Hall, C. S. (1979). A narcissistic personality inventory. Psychological Reports, 45, 590 .

27. Raskin, R., \& Hall, C. S. (1981). The Narcissistic Personality Inventory: Alternative Form Reliability and Further Evidence of Construct Validity. Journal of Personality Assessment, 45, 159-162.

28. Miller, J. D., \& Campbell, W. K. (2008). Comparing clinical and social-personality conceptualizations of narcissism. Journal of Personality, 76, 449-476.

29. Ackerman, R. A., Hands, A. J., Donnellan, M. B., Hopwood, C. J., \& Witt, E. A. (2017). Experts' views regarding the conceptualization of narcissism. Journal of personality disorders, 31(3), 346-361.

30. Wink, P. (1991). Two Faces of Narcissism. Journal of Personality and Social Psychology, 61(4), 590-597.

31. Hendin, H. M., \& Cheek, J. M. (1997). Assessing hypersensitive narcissism: A reexamination of Murray's Narcissism Scale. Journal of Research in Personality, 31(4), 588-599.

32. Wright, A.G.C., Lukowitsky, M.R., Pincus, A.L., \& Conroy, D.E. (2010). The higher-order factor structure and gender invariance of the Pathological Narcissism Inventory. Assessment, 17(4), 467-483. 
33. Wright, A.G.C., Pincus, A.L., Thomas, K.M., Hopwood, C.J., Markon, K.E., \& Krueger, R.F. (2013). Conceptions of Narcissism and the DSM-5 Pathological Personality Traits. Assessment, 20(3), 339-352.

34. Miller, J. D., Dir, A., Gentile, B., Wilson, L., Pryor, L.R., \& Campbell, W.K. (2010). Searching for a vulnerable dark triad: Comparing factor 2 psychopathy, vulnerable narcissism, and borderline personality disorder. Journal of Personality, 78, 1529-1564.

35. Thomas, K.M, Wright, A.G.C, Lukowitsky, M.R, Donnellan, M.B, Hopwood, C.J. (2012). Evidence for the criterion validity and clinical utility of the Pathological Narcissism Inventory. Assessment, 19, 135-45.

36. Thomas, K. M., Wright, A. G. C., Lukowitsky, M. R., Donnellan, M. B., \& Hopwood, C. J. (2016). Correction to "Evidence for the criterion validity and clinical utility of the pathological narcissism inventory.” Assessment, 23(2), 262-263.

37. Miller, J. D., McCain, J., Lynam, D. R., Few, L. R., Gentile, B., MacKillop, J., Campbell, W. K. (2014). A comparison of criterion validity of popular measures of narcissism and Narcissistic Personality Disorder via the use of expert ratings. Psychological Assessment, 26(3), 958-969.

38. Brown, R. P., Budzek, K., \& Tamborski, M. (2009). On the meaning and measure of narcissism. Personality and Social Psychology Bulletin, 35, 951-964.

39. ${ }^{* *}$ Grubbs J.B., Exline, J.J (2016). Trait Entitlement: A cognitive-personality source of vulnerability to psychological distress. Psychological Bulletin, 142, 1204-1226.

This is a comprehensive review of the literature on entitlement, and describes how grandiose features (i.e., entitlement) can place an individual at risk for manifesting vulnerable states (i.e., psychological distress).

40. Edershile, E.A., Simms, L.J., \& Wright, A.G.C. (2017). A multivariate analysis of Pathological Narcissism Inventory's nomological network. Manuscript submitted for publication. 
41. *Sharp, C., Wright, A.G.C., Fowler, J.C., Freuh, C., Allen, J.G., Oldham, J., \& Clark, L.A. (2015). The structure of personality pathology: Both general ('g') and specific ('s') factors? Journal of Abnormal Psychology, 124(2), 387-398.

This paper describes a series of factor models that show that (a) there is little in the borderline personality disorder criteria beyond general personality pathology, and (b) narcissistic features do have shared specific variance.

42. Wright, A.G.C., Hopwood, C.J., Skodol, A.E., \& Morey, L.C. (2016). Longitudinal validation of general and specific structural features of personality pathology. Journal of Abnormal Psychology, 125(8), 1120-1134.

43. Kernberg, O. F. (1985). Borderline conditions and pathological narcissism. Rowman \& Littlefield.

44. Fleeson, W., \& Jayawickreme, E. (2015). Whole trait theory. Journal of Research in Personality, 56, 82-92.

45. DeYoung, C. G. (2015). Cybernetic Big Five Theory. Journal of Research in Personality, 56, 33-58.

46. ${ }^{* *}$ Gore, W. L., Widiger, T. A. (2016). Fluctuation between grandiose and vulnerable narcissism. Personality Disorders: Theory, Research, and Treatment, 7, 363-371. This paper describes a study using innovative methodology and is among the first to empirically demonstrate that narcissistic individuals likely shift between grandiose and vulnerable states. Additionally, the results suggest that narcissistic grandiosity is a specific form of pathology, and that vulnerability by itself likely identifies diffuse personality pathology.

47. Hyatt, C.S., Sleep, C.E., Lynam, D.R., Widiger, T.A., Campbell, W.K., \& Miller, J.D. (2017). Ratings of affective and interpersonal tendencies differ for grandiose and vulnerable narcissism: a replication and extension of Gore and Widiger (2016). Journal of Personality, $1-13$. 
48. Bosson, J. K., Lakey, C. E., Campbell, W. K., Zeigler-Hill, V., Jordan, C. H., \& Kernis, M. H. (2008). Untangling the links between narcissism and self-esteem: A theoretical and empirical review. Social and Personality Psychology Compass, 2, 1415-1439.

49. Geukes, K., Nestler, S., Hutteman, R., Dufner, M., Kufner, A. C. P., Egloff, B., Denissen, J. J. A., \& Back, M. D. (in press). Puffed-up but shaky selves: State self-esteem level and variability in narcissists. Journal of Personality and Social Psychology: Personality Processes and Individual Differences, doi.org/10.1037/psppoo00093

50. Giacomin, M., \& Jordan, C. H. (2016). Self-focused and feeling fine: Assessing state narcissism and its relation to well-being. Journal of Research in Personality, 63, 12-21.

51. Wright, A. G. C., Simms, L. J. (2016). Stability and fluctuation of Personality Disorder features in daily life. Journal of Abnormal Psychology, 125, 641-656.

52. Pincus, A. L., Hopwood, C. J., \& Wright, A. G. C. (in press). The interpersonal situation: An integrative framework for the study of personality, psychopathology, and psychotherapy. In D. Funder, J. F. Rauthmann, \& R. Sherman (Eds.), Oxford handbook of psychological situations. Oxford, UK: Oxford University Press.

53. Ackerman, R. A., Witt, E. A., Donnellan, M. B., Trzesniewski, K. H., Robins, R. W., \& Kashy, D. A. (2011). What does the narcissistic personality inventory really measure? Assessment, $18,67-87$ 
Table 1. Higher-order Narcissism Domains Captured by Different Narcissism Measures

\begin{tabular}{|c|c|c|c|}
\hline \multirow[b]{2}{*}{ Measure } & \multicolumn{3}{|c|}{ Narcissism Domain } \\
\hline & $\begin{array}{l}\text { Exhibitionism } \\
\text { (Grandiosity) } \\
\text { [Extraverted] }\end{array}$ & $\begin{array}{c}\text { Entitlement } \\
\text { (Self-Importance) } \\
\text { [Antagonistic] }\end{array}$ & $\begin{array}{c}\text { Vulnerability } \\
\text { (Vulnerability) } \\
\text { [Neurotic] }\end{array}$ \\
\hline \multicolumn{4}{|l|}{ PNI } \\
\hline Grandiosity & $\mathrm{x}$ & $\mathbf{X}$ & $\mathrm{x}$ \\
\hline Vulnerability & & $\mathrm{x}$ & $\mathbf{X}$ \\
\hline \multicolumn{4}{|l|}{ NPI } \\
\hline Leadership/Authority & $\mathbf{X}$ & $\mathrm{x}$ & \\
\hline Grandiose Exhibitionism & $\mathbf{X}$ & & \\
\hline Entitlement/Exploitativeness & & $\mathbf{X}$ & \\
\hline \multicolumn{4}{|l|}{ FFNI } \\
\hline Grandiosity & $\mathbf{X}$ & $\mathrm{x}$ & \\
\hline Vulnerability & & $\mathrm{x}$ & $\mathbf{X}$ \\
\hline \multicolumn{4}{|l|}{ NARQ } \\
\hline Admiration & $\mathbf{X}$ & & \\
\hline Rivalry & & $\mathbf{X}$ & $\mathrm{x}$ \\
\hline NGS & $\mathbf{X}$ & & \\
\hline HSNS & & & $\mathbf{X}$ \\
\hline PES & $\mathrm{x}$ & $\mathbf{X}$ & \\
\hline
\end{tabular}

Note. $\mathbf{X}=$ scale considered to be primarily captured by the domain; $\mathrm{x}=$ scale considered to be secondarily captured by the domain. Parentheses reflect label used by Krizan and Herlache (2017); Bracketed terms reflect labels used by Miller et al. (2017). PNI = Pathological Narcissism Inventory; NPI = Narcissistic Personality Inventory; FFNI = Five-Factor Narcissism Inventory; NARQ = Narcissistic Admiration and Rivalry Questionnaire; NGS = Narcissistic Grandiosity Scale; HSNS = Hypersensitive Narcissism Scale; PES = Psychological Entitlement Scale. NPI scales based on analyses by Ackerman and colleagues [52]. 
Conflicts of Interest: none 